pharyngula/2006/11/nature_publishes_a_ crank_lette.php\#more.

We worry that Giertych's Correspondence will lend credibility to pseudoscientific efforts to undermine evolutionary theory. Its publication is damaging to Nature's reputation and to science itself. We as scientists may be able to see whether a claim is scientifically thorough, but many other people cannot. We urge the editors to insist on the same scientific rigour in Correspondence as in any other section of Nature.

Uwe Balthasar, Susannah Maidment Department of EarthSciences, University of Cambridge, Downing Street, Cambridge CB2 3EQ, UK

\section{There is no new evidence that undermines evolution}

SIR — We are astonished that Nature would publish a Correspondence as full of errors as that by Maciej Giertych (Nature 444, 265; 2006). For someone with degrees from the universities of Oxford and Toronto, Giertych displays a breathtaking ignorance.

There is no "new scientific evidence against the theory of evolution" as he asserts, but fails to document. This can be verified by consulting any of the recent standard textbooks on the subject. The daim that "microevolution....is a step towards a reduction of genetic information ${ }^{\text {" }}$ is nonsense. On the contrary, there is ample evidence for the frequent use of duplications of genes in evolution, many of which have acquired new functions. By any criterion, this represents an increase in the amount of genetic information.

Contrary to Giertych's statements, the temporal ordering of rock layers by stratigraphy, and the extinction of dinosaurs some 65 million years before the existence of humans, are overwhelmingly established facts of geology and palaeontology. His claim that "No positive mutations have ever been demonstrated ${ }^{\text {" }}$ is simply false. Disregarding the fact that it is illogical to rule out resistance to antibiotics and herbicides as examples of adaptations, as was done by Giertych, there are literally thousands of cases in which natural selection has been demonstrated in wild populations of animals and plants.

Further, the contemporary literature on molecular evolution is filled with studies that provide evidence for a positive role of natural selection. Physicists do not spend their time debating the correctness of the atomic theory of matter; it is intolerable that biologists should constantly be forced to defend their unifying theory against ill-informed attacks. Brian Charlesworth and 34 others (names available on request from B.C.)

Institute of Evolutionary Biology, School of Biological Sciences, University of Edinburgh, Edinburgh EH9 3JT, UK

\section{Walking with dinosaurs? Not in the real world}

SIR - It is to be hoped that Maciej Giertych's comments in Correspondence (Nature 444,265 ;2006) will generate a flood of refutations. Staying within my archaeological profession, Giertych's daims that there are data suggesting that "dinosaurs coexisted with humans" or that there was a "major worldwide catastrophe in historical times" are simply false. These are daims regularly made by religious fundamentalists in support of creationism, exposing Giertych's assertion that his objections are scientific.

In support of these claims, some creationists promote known frauds such as the Paluxy River 'human footprints' and the 'dinosaur figurines' from Acambaro, Mexico, which they misrepresent as modelled from living observations. There are many creationist interpretations of prehistoric rock art that owe more to Hermann Rorschach than to Richard Owen.

Creationists also distort actual science. Mary H. Schweitzer's research on dinosaur tissue preservation has been used for years as 'proof' that Earth is a few thousand years old, as I document in "Dino-blood and the Young Earth" and "Dino Blood Redux" (see www. talkorigins.org). Giertych's Correspondence shows us the irrational basis of creationism in the twenty-first century and warns the international scientific community that this delusion is not restricted to American hillbillies.

GaryS. Hurd

33902 Silver Lantem, Dana Point, California 92629, USA

\section{Creationists pose political, not scientific, threat}

SIR - I was disappointed to see Maciej Giertych's letter ${ }^{\alpha}$ Creationism, evolution: nothing has been proved ${ }^{\prime \prime}$ (Nature 444, 265; 2006) published without any disclaimer or comment by the editors. Even though I am aware that Nature asked Giertych to comment on the News story "Polish scientists fight creationism" (Nature 443, $890-891 ; 2006$ ), I can find no justification for publishing pseudoscientific arguments in this first-rate scientific magazine.

The level of scientific illiteracy in those arguments is self-evident and, as such, does not need any further discussion. What needs some comment is Giertych's daim about the scientific inspiration for his criticism of evolutionary science. Contemporary creationists espousing 'intelligent design' (ID) are careful to avoid mentioning religion - as was Giertych in his recent public statements. Yet Polish readers can refer to his four articles in Encyklopedia "Bialych Plam"
(The Encyclopedia of 'missing pages' volumes 4 and 6, PWE, 2000, 2001). These articles, "Darwin, Charles Robert", "Darwinism", "Evolution", and "Evolutionism", provide a more extensive version of the arguments presented in his Correspondence, and explicitly refer to religion and ID views.

Reasonable criticism is as fundamental to science as natural selection is to adaptive evolution. But what Giertych calls "new scientific evidence against the theory of evolution" could not be published in any serious peer-reviewed journal. In fact, publishing scientific papers is not a significant goal for creationists in Poland or anywhere else - on the contrary, the goal is to replace evolution with some pseudoscience in school curricula, as reported in the News story "Polish scientists fight creationism" (Nature 443, 890-891; 2006). The creationists' movement is dangerous to the general public on political, not scientific, grounds.

\section{Jerzy Banbura}

Department of Experimental Zoology and Evolutionary Biology, University of Lodz, Banacha 12/16, 90-237 Lodz, Poland

\section{How the word 'hominid' evolved to include hominin}

SIR - Human evolution has long been a subject that can daim a love of tonguetwisting terminology, which if not properly explained can lead to much confusion. The latest example is the reassessment of the linnaean description of the relationship between Homo sapiens and the other great apes. To better describe the close evolutionary relationship between them, a new sub-family level has been created. The family group 'hominid' now contains all of the African apes, not just the species of the human lineage; and the newly created sub-family name 'hominin' (with associated sub-families for Pan and Gorilla) contains all the species of the human evolutionary lineage. The term hominin is now used where hominid was previously, causing much confusion, especially among students and nonspecialists.

Publications have a key role in ensuring that this change and the reasons for it are as clear as possible. Yet journals, including Nature, continue to publish papers and features that use the terms hominin and hominid interchangeably. If all in our discipline could agree to the new terminology, journals could ensure that it is used correctly, bringing a small amount of clarity to a subject that so often presents problems of interpretation for the nonspecialist but fascinated public audience. Simon Underdown Department of Anthropology and Geography, Oxford Brookes University, Gipsy Lane Campus, Headingtan, Oxford OX3 OBP, UK 